\title{
Technical error of vertebral rotation measurement directly on the computer screen, according to Raimondi method
}

\author{
Manuel D Rigo*, Monica Villagrasa \\ From 7th International Conference on Conservative Management of Spinal Deformities \\ Montreal, Canada. 20-22 May 2010
}

\section{Introduction}

The purpose of the study was to check the intrarater reliability of the Raimondi system measuring vertebral rotation directly on a computer screen.

\section{Background}

The measurement of vertebral axial rotation according to Perdriolle and to Raimondi is reliable on standard films, where apical vertebrae show a proper size for the scale of both systems. Current digital radiographs are delivered on a CD format (screen) or on a film format, usually with a non proper size for the two above mentioned methods. No system has been described for a rapid assessment of vertebral rotation directly from the screen. Raimondi system, with no needs for reference marks, could be considered a proper tool to be use for that purpose. The size of the apical vertebra can be increased as much as necessary when using CD format as well as digital photography. However this could be considered, together with other factors, a source of error.

\section{Methods}

Vertebral rotation was measured according to Raimondi twice by the same observer on 45 apical vertebrae (thoracic, thoracolumbar and lumbar) from a set of 27 radiographs (12 CDs and 15 digital photos) directly on the computer screen.
Institut Elena Salvá, Barcelona, Spain

Full list of author information is available at the end of the article

\section{Results}

Intrarater reliability was $\mathrm{r}=.968(\mathrm{r}=.991$ on standard films). The mean intrarater error was 2.4 degrees (0.4 degrees on standard films).

\section{Discussion}

No rapid and practical way to measure vertebral rotation has been shown when assessing scoliosis directly from CDs. On the other hand, when patients provide films from digital radiographs, such a films use to be too small in a way that the transversal diameter of the apical vertebra is less than $20 \mathrm{~mm}$. Thus, nor Perdriolle method neither Raimondi are useful tools to measure vertebral rotation on those films. An alternative method is to use a digital photo from the film, which can be managed to change the size of the apical vertebra by using any of the common photo viewers available in PCs. Raimondi method needs no reference marks and showed good intrarater reliability as well as a low mean measurement error when used on standard radiographs. For this reason it was considered the best candidate method to use for direct measurements of the vertebral rotation on the computer screen from both CDs and digital photos. Although intrarater reliability is still good, the results of this study does not reproduce those from previous studies when measuring on classical radiographs, suggesting that errors could come from different sources: the screen itself or variability produced by the change of the vertebral size when looking for a proper proportion to use this particular method.

\section{Conclusions}

Raimondi method is useful and practical tool for the measurement of vertebral rotation directly on a computer screen in a busy clinical setting; however, due to the 
relatively high mean intrarater error found in this present study, it should be used cautiously, even by an experience clinician, when making decisions.

Published: 10 September 2010

doi:10.1186/1748-7161-5-S1-014

Cite this article as: Rigo and Villagrasa: Technical error of vertebral

rotation measurement directly on the computer screen, according to

Raimondi method. Scoliosis 2010 5(Suppl 1):014.

Submit your next manuscript to BioMed Central and take full advantage of:

- Convenient online submission

- Thorough peer review

- No space constraints or color figure charges

- Immediate publication on acceptance

- Inclusion in PubMed, CAS, Scopus and Google Scholar

- Research which is freely available for redistribution

Submit your manuscript at www.biomedcentral.com/submit 